\title{
Does Social Media Promote the Public's Perception of the Police: Survey Results On Trust Cultivation
}

\author{
Christine B. Williams \\ Bentley University \\ cwilliams@bentley.edu
}

\author{
Jane Fedorowicz \\ Bentley University \\ jfedorowicz@bentley.edu
}

\begin{abstract}
Police departments use social media to inform the local community. Additionally, police share selfpromotional information to enhance the public's perception of law enforcement. Research using cultivation theory shows that reliance on a media source such as television cultivates viewer perceptions of a subject. We apply cultivation theory to this interactive medium to test whether viewing and responding to social media messages increases followers' satisfaction with the police. Surveys administered online to the followers of four police departments show that followers who view and respond to police posts more frequently are also inclined to be more satisfied with the police. Minorities are less satisfied with police than whites, but not significantly so. Finally, followers who like (dislike) police self-promotion are more (less) satisfied with police. The findings provide partial support for applying cultivation theory to the social media setting and suggest that police use of social media can help achieve community policing goals.
\end{abstract}

\section{Introduction}

Public perception of U.S. police departments is mixed, ranging from extreme hostility to neighborly trust. The hostility derives from highly publicized brutality incidents, especially against minorities. Local positive interactions accompany police sponsorship and participation in community social celebrations. In both extremes, police departments want to increase their local community's level of trust in the police, believing a positive relationship with the community enhances their ability to ensure public safety. Efforts to increase trust take the form of increased foot patrols, participation in positive community social events, and interacting with constituents using common social media platforms. In light of current public safety concerns, this paper investigates whether social media outreach can improve public perceptions of the police.

Police use of social media has grown dramatically in the past few years. A nationwide survey of social media use by 500 U.S. law enforcement agencies in 2016 finds that 94 percent use Facebook, followed by Twitter (71.2\%) and YouTube (40.0\%) [1]. Social media offer a convenient, effective communication channel for law enforcement agencies to interact with the public. Common messaging activities include broadcasting and announcing public safety-related events (e.g., traffic conditions and inclement weather warnings), disseminating self-defense and property protection tips, reporting event status and updates, and calling for assistance with policing activities (e.g., criminal investigations). These activities and interactions are intended to increase public awareness and build trust within the community, that is, to help achieve the goals of community policing.

This paper updates cultivation theory to examine public perceptions of police and their use of social media. Social media differs from older static (newspaper) and unidirectional (television) media, as it allows for immediate, two-way interaction. Cultivation theory originally measured the influence of media viewing (historically, television) on its viewers' beliefs and perceptions [2]. It postulates that "heavy" viewers' (in contrast to "light viewers") perceptions of social reality differ, particularly their fear of crime, and these perceptions correlate with television portrayals rather than with real world circumstances [3]. The current study follows a recent trend toward testing more micromeasures of exposure to specific programming or messages [3], which, we suggest, are more relevant in this era of mediated interpersonal communication and fragmented audiences [4]. Rather than investigate the effect of particular categories of message content (i.e., violent television content on viewers), we expand the theory by proposing and testing its effects on users' perceptions of the entity doing the communicating. 
To investigate the relationship between followers' frequency of viewing and responding to police messages to satisfaction with their local police department, we conducted a survey of Twitter and Facebook followers of four police departments. The analysis assesses whether those who interact more with the police over social media are inclined to hold more positive perceptions of the police, in line with our expectations from cultivation theory. Demographic differences in police satisfaction rates are noted based on minority status of the responding follower, which is consistent with prior research on racial differences in perceptions of the police.

The remainder of the paper proceeds as follows. We first briefly review the literature on police use of social media. The next section describes our method of data collection based on surveys of current Facebook and Twitter users for four U.S. police departments: Billerica, MA; Omaha, NE; Sparks and Washoe County, NV. A presentation of the findings follows in which we explore survey respondents' opinions of the locale's use of social media by police. We then examine whether the level of respondents' interactivity with those accounts, their preferences for post content, and evaluation of the departments' social media outreach influence their police department ratings. Such knowledge can help police leverage their social media outreach more effectively. The paper concludes with a discussion of the findings and limitations of the study and proposes directions for future research.

\section{Public Response to Police Social Media}

The public generally is supportive of law enforcement agencies, but their responses to police departments' social media presence are limited as indicated by the number and frequency of posts, comments or likes [5]. An analysis of Facebook activities of four metropolitan police departments reveals that they employed different social media management strategies, which caused different patterns of audience engagement [6]. Some types of Twitter messages are more likely to be forwarded and shared by the audience than others [7], and police officers' presentation strategies in Twitter messages can affect the public's perceptions of the police [8].

In terms of social media impact on policecommunity relations, studies have found that social media use by police departments increases public confidence (trust) and satisfaction (effectiveness and perceived legitimacy) [9-11]. A related study found

\footnotetext{
${ }^{1}$ https://cops.usdoj.gov/pdf/vets-to-cops/e030917193-CPDefined.pdf
}

that social media use increased both trust in and satisfaction with government agencies [12]. Warren et al. [13] report that using social media for civic engagement has a significant positive impact on trust propensity and that this trust had led to an increase in trust towards institutions. To enhance trust among the public the authors recommend fostering social capital via online civic engagement to close the public-police disengagement gap. Collectively this evidence reveals that social media has the potential to facilitate increased engagement between a police department and its community, with some potential for enabling the goals of community policing.

\section{Community Policing}

Current thinking suggests that police departments that encourage positive interaction with their communities engender higher levels of trust than those that focus only on fighting crime. The "community policing" philosophy promotes organizational strategies involving partnerships and problem-solving techniques to proactively address the immediate conditions that give rise to public safety issues, such as crime, social disorder, and fear of crime ${ }^{1}$. A key assumption is that increasing police community collaboration, along with sensitivity toward the differential needs and priorities of different communities, will enhance the overall image of police as caring and concerned about community needs, and thereby further collaboration. If social media can be shown to enhance positive perceptions of police, then it becomes a valuable tool in support of community policing.

A number of studies provide confirmatory evidence. Weitzer and Tuch [14] find that the presence of community policing increased satisfaction with police while frequent exposure to negative media coverage of police misconduct decreased satisfaction. In their literature review Zhao, et al. [15] conclude that police presence has a strong impact on reducing public fear of crime and a successful fear reduction program increases public satisfaction with police services. Hawdon and Ryan [16] report that both greater policeresident interaction and a visible neighborhood presence increase resident satisfaction; in addition, community policing substantially lowers fear of crime. Schneider, et al. [17] found that perceptions of community policing have strong positive effects on satisfaction with police and crime prevention behaviors. Grimmelikhuijsen et al. [15] conclude that overall, establishing a direct channel with citizens and 
using it to communicate successes helps the police to strengthen their legitimacy slightly. In their review of 25 studies of community policing in the U.S., Gill, et al. [18] conclude that community-oriented policing strategies have had positive effects on citizen satisfaction and police legitimacy.

It is apparent from their high adoption rates that police departments are optimistic that social media activity can improve at least some aspects of their relationship with the community. The identification of a relationship between communication media and relationship-building is not new to social media. For example, in a study of online discussion groups, a forum analogous to that which social media affords, Brainard and Derrick-Mills [19] find that these groups provide an opportunity for interaction that could lead to the relationship-building necessary to support mutuality and the spirit of reciprocal cooperation. The similarity of discussion group affordances to those of social media lends credence to the expectation that social media usage carries the potential to cultivate trust and support community policing efforts. This study is a first look at whether frequent social media interaction with police through social media can be instrumental in relationship building. Cultivation theory suggests that it will be.

\section{Cultivation Theory}

Cultivation theory proposes that media chosen for information acquisition will sway the belief set of those receiving the information. In particular, Gerbner's cultivation theory assesses the impact that amount of television viewing has on opinions, images and attitudes [20]. It supposes that those who watch more television are more likely than those who watch less to perceive the real world in ways that reflect television's common and recurrent messages. The messages disseminated by television reflect the values and priorities of the institutions that create them. That content includes a variety of issues and topics such as political orientations, cultural stereotypes and social norms [21]. The amount of viewing often interacts with other personal or social location factors (e.g., demographic group identity).

In Gerbner's theory, heavy viewing tends to "mainstream" those who otherwise have little in common into sharing beliefs consistent with television messages. While television viewing does not necessarily change attitudes, it appears to make them stronger [20]. Now that new communications media are shrinking and fragmenting broadcast network audiences, we expect an impact on this cultivation. Morgan [20] suggests that change will depend on whether new media's messages change (from television's) and diverge from each other.

People have relied on a variety of media over time to learn about what is happening in the world around them. Choice of media is predicated on reliability and/or timeliness of access to new information. Newspapers are less timely than television, and social media gives instantaneous access that these other media cannot. Unlike television, social media is a twoway channel, which is also likely to increase the appeal of this as a medium of choice. While traditional cultivation analyses focus on the impact heavy (television) viewing has on attitudes, and especially the fear of crime, we have flipped the focus to examine its impact on assessment of the police as the producer of the content shared via this medium, as that is the direction that is both controlled by police and gives them access to a broad swath of the local community.

\section{Research hypotheses}

This paper investigates how the frequency of viewing and interacting with social media affects, or cultivates, evaluations of police. Consistent with cultivation theory, it analyzes whether different levels of exposure result in different perceptions of police. This single metric does not account for additional factors such as job performance or crime rate that might also shape perceptions. Rather, we meld those predispositions toward police into a surrogate indicator, in which individuals like or dislike police promotional posts. This allows survey respondents to self-indicate among those who are favorably and unfavorably predisposed toward police. We also include mediating personal and social position factors of race and attitudinal predisposition toward police in the analysis. Hypotheses $\mathrm{H} 1, \mathrm{H} 2$ and $\mathrm{H} 3$ constitute our primary independent variables that operationalize cultivation analysis' main effects. H4 incorporates a control variable, and $\mathrm{H} 5$ captures an additional mediating variable; both of these represent personal, demographic or social location factors that have been known to affect cultivation.

As presented above, studies show that both police presence and police-resident interaction increase citizen satisfaction. Having a social media account is a contemporary way that police can make themselves present (virtually) to the community. For example, during an emergency, Twitter disseminates information faster and more widely than broadcasts and is a highly popular medium in those circumstances [22]. How frequently respondents view posts on those accounts indicates the degree to which they are exposed to that presence. Exposure is the key driver in cultivation analysis theory. Similarly, the frequency 
with which these followers respond to police posts is indicative of their level of interaction with police, albeit not face to face. Both indicators offer direct means of determining not only that respondents saw these posts, but they engaged with them, and operationalize the degree to which they have done so. As cultivation analysis is premised upon comparison of "heavy" vs. "light" consumption of media communications, we can make the following directional predictions:

H1: Frequency of viewing police social media posts increases followers' ratings of satisfaction with their police.

$\mathrm{H} 2$ : Frequency of responding to police social media posts increases followers' ratings of satisfaction with their police.

The evidence cited above contends that community policing programs lead to greater satisfaction, while exposure to negative media coverage reduces satisfaction. In a similar manner, Quick [23] uses cultivation theory to show viewers' perceptions of television program credibility is positively associated with the perception that the actors' real-world counterparts are courageous. Putting the observation that exposure generates satisfaction together with the finding that satisfaction positively influences perceptions, we predict:

H3: The higher followers' ratings of police social media outreach efforts are, the higher they will rate satisfaction with their police.

Race appears to be a strong indicator for police approval. Howell, Perry, \& Vile [24] note that historically, the relationship between minorities and the police has been especially challenging, "fluctuating from being mildly strained to openly confrontational" (p. 45). For example, a George Mason University report [25] finds that among demographic characteristics associated with the general image of police, whites (in contrast with blacks) have more positive attitudes. A study by Cheurprakobkit [26] shows that Spanish-speaking Hispanics felt more satisfied with police performance than whites and English-speaking Hispanics; and blacks had less favorable attitudes toward the police than either whites or the two Hispanic groups. In a more recent study, Morin and Stepler [27] find that roughly three-quarters of whites but only about a third of blacks rate police in their communities as excellent or good on various job performance categories. Based on this research, we include race as a control variable in our models with the expectation that minorities will evaluate their police significantly less favorably than whites, above and beyond the impact of their social media engagement (our independent variables).

H4: Minorities are less satisfied with their police than are whites, given equivalent rates of social media views and responses.

An important study by Rosenbaum, et al. [28] shows that residents' initial attitudes about the police play a critical role in shaping their judgments of subsequent direct and indirect experiences as well as their future attitudes. Also, positive information about the police produced larger attitudinal effects than negative information. They explain these findings in terms of confirmation bias (or other researchers would say cognitive dissonance), which has shown that people seek information that is consistent with their stereotypes of other groups and avoid disconfirming information. In essence, a message aiming to endorse a positive perception of the sender should be perceived differently than a message that distributes communityoriented facts or news. Our survey breaks down the types of messaging into categories that can be used to look more closely at self-promoting vs. newsspreading posts. Taking respondents' attitudes toward police posts promoting their activities and image as indicators of an initial predisposition to like or dislike police, we make the following predictions about impact on ratings of their police. $\mathrm{H} 5 \mathrm{a}$ and $\mathrm{H} 5 \mathrm{~b}$ measure confirmation bias and cognitive dissonance, respectively.

H5.a: Those who select promotional posts as most liked are more satisfied with their police than those who do not select them.

H5.b: Conversely, those who select promotional posts as most disliked are less satisfied with their police than those who do not select them.

\section{Data and Method}

This paper reports analyses of the responses to our electronic survey about social media practices gathered from users of four U.S. police departments' Facebook and Twitter accounts: Billerica, MA; Omaha, NE; Sparks, NV; and Washoe County, NV. Heuristics guiding our selection of these cases included indicators of national reputation as evidenced by social media activity (such as frequency of posts, followers, friends and impressions of posts) along with municipal rankings declaring finalists for the SM Excellence Awards from Connected Cops for 
2012, 2013, and 2014²; the 50 Most Social Media Friendly Police Departments in America's Largest Cities $^{3}$; U.S. Law Enforcement Agencies with the Most Twitter Followers ${ }^{4}$ or Facebook "Likes"5; The Best Social Media Cities ${ }^{6}$; and Top 10 Most TechFriendly Cities ${ }^{7}$. Many of these lists include subcategories by police department/city size assisting in the selection of the top performing police departments stratified by population.

Based upon U.S. Census Bureau estimates for 2017 as reported in Table 1, these locales represent U.S. communities of different sizes and racial composition. Demographic analysis shows that there is little difference in the age, gender or educational attainment of the four samples' respondents. In contrast, four of six town-by-town t-tests checking difference in racial composition are significant (see Table 1), which further justifies why it is the only demographic variable included in this study.

The research team developed the survey, with pilot feedback from the police departments. We provided a Spanish translation of the survey in addition to the English version and the few responses received in that language are folded into this analysis. We posted the surveys on Facebook and Twitter between January 19 and March 22, 2017. The Facebook and Twitter surveys are identical except for replacing the name of the platform about which we ask the questions.

Table 1. Comparison of sample locations by population and race

\begin{tabular}{|l|c|c|}
\cline { 2 - 3 } \multicolumn{1}{c|}{ Location } & Population & $\begin{array}{c}\text { Percent } \\
\text { White }\end{array}$ \\
\hline Billerica, MA & 43,962 & $87.2 \%$ \\
\hline Omaha, NE & 466,893 & $67.2 \%$ \\
\hline Sparks, NV & 100,888 & $59.3 \%$ \\
\hline Washoe County, NV & 460,587 & $61.4 \%$ \\
\hline
\end{tabular}

Table 2 shows the totals by town after we deleted surveys of respondents who completed only a few questions. Our individual analyses also deleted on a case by case basis those where one of the responses of interest was missing. For context we include the total number of account followers for each location at the time of the survey. Where necessary, extrapolations of 2016 and 2018 data generated a 2017 estimate.

\footnotetext{
${ }^{2}$ http://connectedcops.net/2014/08/15/the-2014connectedcops-awards-finalists-are/

${ }^{3}$ http://mphprogramslist.com/50-most-social-media-friendlypolice-departments/

${ }^{4}$ http://www.iacpsocialmedia.org/Directory/AgencyTwitterStat istics.aspx
}

Table 2. Survey responses and number of followers by location and platform

\begin{tabular}{|c|c|c|}
\cline { 2 - 3 } \multicolumn{1}{|c|}{} & Facebook & Twitter \\
\hline \multicolumn{3}{|c|}{ Billerica, MA } \\
\hline Responses & 261 & 126 \\
\hline \# Followers & $8.8 \mathrm{~K}$ & $19.1 \mathrm{~K}$ \\
\hline \multicolumn{3}{|c|}{ Omaha, NE } \\
\hline Responses & 196 & 233 \\
\hline \# Followers & $95.7 \mathrm{~K}$ & $70.1 \mathrm{~K}$ \\
\hline \multicolumn{3}{|c|}{ Sparks, NV } \\
\hline Responses & 137 & 33 \\
\hline \# Followers & $8 \mathrm{~K}$ & $2.5 \mathrm{~K}$ \\
\hline \multicolumn{2}{|c|}{ Washoe County, NV } \\
\hline Responses & 74 & 49 \\
\hline \# Followers & $14.9 \mathrm{~K}$ & $4.2 \mathrm{~K}$ \\
\hline
\end{tabular}

Our dependent variable is the respondents' rating of their own police department (Rate SM), measured on a five-point scale: "poor"; "not very good"; "neither good nor bad or mixed (some good some not so good); "good"; and "excellent".

We investigate the impact of three independent variables on respondents' ratings, as collected by the questions that follow: View: How often do you look at the Police Department's <Twitter/Facebook> account or see a post from them?; Respond: How often do you respond to something on the Police Department's <Twitter/Facebook> account? (both coded on a five-point scale from "never"; "few times a year"; "few times a month"; few times a week"; to "daily") and RateSM: How would you rate the Police Department's outreach through this $<$ Twitter/Facebook> platform? (coded using the same five-point scale as the dependent variable). In each case, the survey questions inserted the name of the specific Police Department and the name of the social media platform $\langle$ Twitter/Facebook $\rangle$ that respondents were being asked to evaluate.

Because of the low number of racial minorities choosing to respond, we had to collapse the eight race categories into two, white and minority (non-white), to have sufficient power for analysis.

${ }^{5}$ http://www.iacpsocialmedia.org/Directory/AgencyFacebook $\underline{\text { Statistics.aspx }}$

${ }^{6}$ http://www.govtech.com/wireless/Best-Social-Media-Cities2012.html

${ }^{7}$ http://www.scientificamerican.com/article/the-top-10-citiesfor-techology/ 
We operationalized the independent variable in hypothesis 5 as the percentage of respondents who identified posts promoting the police department as either those that interested them most (Promo Like used in H5a) or interested them least (Promo Dislike used in H5b). We coded the response 1 if they selected that category and 0 if they did not select it. "Promotions" represents one of 10 choices provided as topical content for police social media posts and was the only choice that was relevant to test hypotheses on confirmation bias/cognitive dissonance relative to satisfaction with the police. (In addition to Promotional posts these content categories were: Accidents, Announcements, Crime, Events, Interactions with or responses to individuals, Property and pets, Safety, Traffic problems, and Weather, topics related to another study within our program of research.)

As the variables tested in our hypotheses measure ordinal (ranked) data, we adopted ordinal logistic regression for our analysis.

Before conducting our multivariate analysis, we examined the zero order correlations of each of the independent variables with the dependent variable, police department rating. Table 3 reports the ordinal measure of association Kendall's tau (b for square tables and c for rectangular tables) together with the significance level of each coefficient. Their absolute values range from .06 to .47 ; they are in the expected direction, and all are statistically significant at $\mathrm{p}<.01$. These results indicate that each independent variable has some direct effect on our dependent variable. Our check for multicollinearity among these predictor variables showed very weak intercorrelation, which therefore is not a concern. We conclude that we can proceed with the variables and proposed multivariate regression analysis as described above. We present the findings relative to our hypotheses in the next section.

Table 3. Zero Order Correlations

\begin{tabular}{|l|c|r|}
\hline & Kendall's Tau & Sig. \\
\hline Respond & +.134 & .000 \\
\hline View & +.189 & .000 \\
\hline Rate SM & +.466 & .000 \\
\hline Race & +.057 & .004 \\
\hline Promo Like & +.253 & .000 \\
\hline Prom Dislike & -.164 & .000 \\
\hline
\end{tabular}

\section{Findings}

Our first task was to test whether the four locations could be combined to form a single data set. This was desired as there would not be sufficient numbers of minority respondents to include race as a variable (in $\mathrm{H} 4$ ) if running these regressions individually. Of the six pairs of locale-by-locale t-tests for demographic differences, race had the largest number of significant results: four of the six were significant, adding a methodological reason to our substantive rationale for including it as a variable in the regression.

As a precaution before combining data sets, we also tested the effect of location by including it as a control variable; however, none of the coefficients in a regression including the town dummy variables was significant. Given the differences in population size, we then ran a regression model including a scaled variable for town size (small, medium or large), but that also proved not to be significant. Based on these results, the reported analyses combine the four locations.

Because ordinal logistic regression estimates are sensitive to the distribution of responses across rankings, it was necessary to collapse some categories to produce a more equal distribution. The resulting three categories for the two recoded independent variables are frequency of viewing "never", "a few times a year" and "a few times a month" => "rarely" (coded 1); "a few times a week" (coded 2) and "daily" (coded 3). The collapsed categories for frequency of responding are "never" (coded 0); "once" and "a few times a year" $\Rightarrow>$ "infrequently" (coded 1); and "a few times a month," "a few times a week" and "daily" => "often" (coded 2).

The final model shown in Table 4 includes the three main cultivation variables (frequency of viewing and responding to posts plus evaluation of social media outreach) captured in hypotheses 1,2 and 3, the additional predispositional variables in hypotheses $5 \mathrm{a}$ and $5 \mathrm{~b}$, together with the variable representing race (hypothesis 4). Note that in ordinal logistic regression the estimates for the variables use the highest value as the reference category, which are indicated by the table's footnote. We next provide an overview of the interpretation of the estimate coefficients and their signs for each of the hypotheses.

Those who rarely view their police social media posts are the least approving (H1) and likewise, those who never respond to posts are also the least approving (H2). Although in the direction expected by our hypotheses, the estimates for these two variables are not significant, noting that the value "rarely" on viewing frequency is very close at .056 . 
Turning to $\mathrm{H} 3$, relative to those who rate police social media outreach as excellent, those who rate it as poor are least approving of their police, and all ratings are significant. The followers who express the lowest approval of police social media activity have the lowest level of satisfaction with the police. In both cases these coefficients are significant.

For H4, relative to whites, minorities are somewhat less approving of their police department (but not significantly, at .072). However, additional analysis of the bivariate relationship between race and the dependent variable police satisfaction shows a mean difference of .270 that is significant $(\mathrm{p}=.002)$. We further note that looking again at just the bivariate relationship between race and three of the independent variables - social media outreach rating, like promotional posts and dislike promotional posts - the t-tests of mean differences are significant and in the predicted direction. Only the frequency with which whites and non-whites engaged (viewed and responded to posts) with police social media are not significantly different. This suggests a more complex direct and indirect effects model, which is beyond the scope of our data and analysis in the current study.

Finally, for $\mathrm{H} 5 \mathrm{a}$, relative to those who like promotional posts, those who dislike them are significantly less approving; and for $\mathrm{H} 5 \mathrm{~b}$, relative to those who dislike promotional posts, those who do not dislike them (i.e., did not indicate a dislike) are significantly more approving. These H5 estimates are significant, which indicates an inverse relationship of preferences with respect to liking or disliking promotional posts. To the extent feelings about promotional posts serve as a surrogate for pre-existing attitudes toward police regardless of their cause, suggests exposure levels ( $\mathrm{H} 1$ and $\mathrm{H} 2$ ) probably reinforce rather than change these strongly significant effects.

Ordinal logistic regression does not have an equivalent to the standardized Beta coefficient in ordinary least squares (linear) multiple regression to indicate the relative importance of independent variables. Table 4 also reports that the final model fit is significant at .000 and the goodness of fit coefficient is significant at 1.000 , indicating both are at the maximum desired value. Finally, the pseudo R squared indicates that the variance explained by the model is .374 or $37 \%$ of the total, which suggests these variables have a reasonable impact on respondents' evaluations of their police department. Social media appears to produce a positive contribution to policepublic communications.
Table 4. Ordinal logistic regression results

\begin{tabular}{|c|c|c|}
\hline Independent variables & Estimate & Sig. \\
\hline \multicolumn{3}{|l|}{ Respond } \\
\hline$[$ Never $=.00]$ & -.207 & .309 \\
\hline [Infrequently=1.00] & .161 & .466 \\
\hline Often $=2.00]$ & $0^{a}$ & \\
\hline \multicolumn{3}{|l|}{ View } \\
\hline [Rarely=1.00] & -.547 & .056 \\
\hline$[$ Few $\times$ Week=2.00] & -.171 & .345 \\
\hline [Daily $=3.00]$ & $0^{\mathrm{a}}$ & \\
\hline \multicolumn{3}{|l|}{ SM outreach } \\
\hline$[$ Poor $=1]$ & -6.388 & .000 \\
\hline [Not very good=2] & -3.017 & .000 \\
\hline$[$ Mixed=3] & -3.386 & .000 \\
\hline [Good=4] & -1.566 & .000 \\
\hline [Excellent=5] & $0^{\mathrm{a}}$ & \\
\hline \multicolumn{3}{|l|}{ Race } \\
\hline$[$ Minority=.00] & -.499 & .072 \\
\hline$[$ RaceWhire $=1.00]$ & $0^{\mathrm{a}}$ & \\
\hline \multicolumn{3}{|l|}{ Like promo } \\
\hline$[\mathrm{No}=.00]$ & -.590 & .001 \\
\hline [Like Yes=1.00] & $0^{\mathrm{a}}$ & \\
\hline \multicolumn{3}{|l|}{ Dislike promo } \\
\hline$[\mathrm{No}=.00]$ & .571 & .006 \\
\hline [Dislike Yes=1.00] & $0^{a}$ & \\
\hline
\end{tabular}

Final Model Fitting

\begin{tabular}{c|c|c} 
Chi-Square & df & Sig. \\
\hline 291.888 & 11 & .000 \\
\hline
\end{tabular}

\begin{tabular}{|c|c|c|c|}
\hline \multicolumn{4}{|c|}{ Goodness-of-Fit } \\
\hline & $\begin{array}{r}\text { Chi- } \\
\text { Square } \\
\end{array}$ & df & Sig. \\
\hline Pearson & 374.623 & 553 & 1.000 \\
\hline Deviance & 291.582 & 553 & 1.000 \\
\hline
\end{tabular}

\section{Pseudo R-Square}

Nagelkerke .374

\section{Discussion}

In the past, police departments relied on their public information departments to dispense important information to community media for dissemination. 
Before the Internet, the public viewed newspapers and television as their primary source of information. According to cultivation theory, the more that an individual viewed a media source (i.e., television), the more that viewer reflected the values it espoused.

Since the advent of Internet news sources, traditional media have lost some of their influence by dint of the speed, ease and cost of access of this alternative.

The advent of social media disparaged these older media as less timely, even though their reliability and integrity may surpass that of unverified social media posts. Police recognized that the public information office could take advantage of the speed of the Internet coupled with their continuing integrity as a verified information source. Indeed, a comparative study of social media use by different kinds of organizations by Bird, Ling and Haynes [29] showed that users perceive government agency communications to be more accurate than those of community organizations.

To offset the potential for rapidly spreading falsehoods and rumors, police create their own social media accounts to inform the local community of important news and events. Additionally, police share self-promotional information to enhance the public's perception of law enforcement. We studied public perceptions of the police and their social media activity to detect a relationship between public reaction to posts and their ratings of their police department and to determine whether the expected positive result was achieved.

We applied cultivation theory [30] to this interactive medium, to test whether viewing and responding to social media messages increases followers' satisfaction with the police. Since cultivation theory was developed for one-way sharing, our work constitutes an extension of the theory to news accessed - and responded to or reshared - in real-time over a broadly accessible platform.

Results of the study are mixed. Although directionally these estimates were as expected, frequency of viewing (H1) and frequency of responding $(\mathrm{H} 2)$ to police posts were not statistically significant indicators of followers' satisfaction with police. The negative sign indicates that the least frequent viewers rate their police more negatively than more frequent viewers, which would be expected based on cultivation theory. Comparing those who never respond to police posts with those who do so infrequently and the reference group who respond often, the ratings of the former are negative. It is likely the coefficients for $\mathrm{H} 1$ and $\mathrm{H} 2$ would attain significance with a larger sample size. As Table 3 shows, both zero order correlations with the dependent variable are significant. Undoubtedly, quality and message content, not just the frequency of interactions, matter. Such avenues of inquiry would advance cultivation analysis further into the exploration of micromeasures [3].

We also found that followers with the dimmest perception of police social media outreach had the lowest ratings of their police, and these ratings became less negative as evaluations of police social media outreach improved from poor to excellent (H3). This shows that a predisposition about the media source increases the likelihood that the individual would like the messages shared by the media, which does corroborate cultivation theory. That these coefficients are significant suggests preexisting perceptions of police are more important than social media consumption and interaction in and of itself. We turn finally to considering how people experience policing in their community as a mitigating factor in their performance judgments.

A perception exists in research and in many communities that minorities often have a low opinion of law enforcement. Although our model results are in this predicted direction, the difference in satisfaction with the police (H4) is not significant (at .07) in our regression analysis. However, further analysis involving the race variable shows significance in bivariate testing of the impact of race (alone) on the dependent variable (Table 3 ) as well as in the impact of race on the other independent variables. Evidently race plays a role in social media behavior here, but how it exhibits relative to perceptions of the police department is less clearly evident in the ordinal regression results.

Collectively these various findings on race present a mixed picture worthy of further investigation. They may indicate a more equitable perspective is in place in these locations. We also might attribute it to the low response rate from the minority population in each locale, which forced us to collapse all non-white race categories into the single "non-white" category and into a single, combined data set. If communities create homophily, the town with the lowest percentage of minorities might differ from one where the percentage of minorities is high. Indeed, that is essentially what Hawdon and Ryan [16] found when comparing black suburbanites with both black and white urban residents: the former were more satisfied than either of the other two groups. It also may mean that a survey posted to a police department social media account attracts a sample that is disproportionately skewed to those with more positive predispositions toward their police. Or it may indicate that minorities who hold the police in disfavor are less likely to follow police social media, leading to a smaller non-white proportion from 
which respondents self-select than in the community at large. Additional research is needed to explore more definitively the role of race in perceptions about the police.

A final set of analyses focused on the portion of police postings that are intended to improve the public's perception of the department, in contrast to those that share information on events, crime, or other external activity. These promotional posts are presumed to capture predispositions toward police: a resident with an unfavorable view will not be impressed by glowing portrayals but someone favorably disposed likely appreciates and even applauds such credit taking. These predispositions mattered, and more significantly so than the exposure and interaction levels. These efforts appear to be effective, as those who like (dislike) promotional posts are significantly more (less) satisfied with the police. The aim to increase familiarity and thereby trust with the department appear to advance at least some goals of community policing.

These findings amount to good news for police social media programs. They demonstrate that members of the community who appreciate their social media activity also are likely to rate the department itself highly. Social media does take on the face of the department for those who follow the site, and somewhat more so for those who do so actively. Admittedly many do not; we simply argue that social media is becoming an additional vehicle for advancing community policing goals.

This study also contributes to research on both cultivation theory and social media more broadly. It confirms the direction, though not the strength (the coefficients were not significant) of the predicted relationship. On the other hand, follower interaction itself does seem to have longer reaching benefits, as those who look favorably upon social media also are more inclined to rate their police department more highly, which advances the goal of cultivation increasing positive perceptions. That is, those followers who appreciate self-promotional posts are also more likely to rate the police highly, confirming cultivation theory's point about strengthening attitudes as a result of media messaging [20].

The study is not without its limitations. We acknowledge possible selection bias in our choice of cities whose social media presence is highly ranked. This is the tradeoff incurred when trying to remove extraneous variation from the sample. Perhaps different selection criteria would increase variation in this measure and shed more light on potential causality. Our sample is not large, which likely contributed to the finding of non-significant regression coefficients. Given the distribution method (postings placed on the police social media page/account) the best mechanism for extending the sample size would be to offer it in more or larger locations, especially those with differing racial, educational or economic characteristics than the ones already studied.

This research is an important first step in understanding the way in which social media messaging achieves benefits. Other institutional factors related to police activity and presence (e.g., crime rate or recent racial incidents that could create neighborhood homophily effects) should be added to the model to better separate the import of social media activity from public perceptions obtained elsewhere. Future research also should capture more detailed data on other police functions and characteristics to determine the value of social media as a community policing element. Finally, closer replication of cultivation theory should incorporate added data collection methods such as follower observation or social network analysis of followers to produce parallel, comparative analyses between various traditional media and new media.

\section{Acknowledgment}

We thank our police contacts in the four participating departments for their feedback on the survey process and their assistance in posting the survey online. We also acknowledge the financial support of the Bentley University Data Innovation Network.

\section{References}

1. Kim, K., A. Oglesby-Neal, and E. Mohr, 2016 Law Enforcement Use of Social Media Survey. 2017.

2. Gerbner, G., Cultural indicators: The case of violence in television drama. The Annals of the American Academy of Political and Social Science, 1970. 388(1): p. 69-81.

3. Potter, W.J., A critical analysis of cultivation theory. Journal of Communication, 2014. 64(6): p. 1015-1036.

4. Morgan, M., \& Shanahan, J., The state of cultivation. Journal of Broadcasting \& Electronic Media, 2010. 54: p. 337-355.

5. Neiger, B., Smith, Amanda, Thackeray, Rosemary, Van Wagenen, Sarah, Adoption and use of social media among public health departments. BMC Public Health, 2012. 12(1): p. 242. 
6. Huang, Y., et al. Municipal Police Departments on Facebook: What Are They Posting and Are People Engaging? in Proceedings of the 17th International Digital Government Research Conference on Digital Government Research. 2016. ACM.

7. Van De Velde, B., A. Meijer, and V. Homburg, Police message diffusion on Twitter: analysing the reach of social media communications. Behaviour \& Information Technology, 2015. 34(1): p. 4-16.

8. Schneider, C.J., Police presentational strategies on Twitter in Canada. Policing and Society, 2014: p. 1-19.

9. Grimmelikhuijsen, S. and A. Meijer, Does Twitter Increase Perceived Police Legitimacy? Public Administration Review, 2015. 75(4): p. 598-607.

10. Meijer, A.J., New media and the coproduction of safety: An empirical analysis of Dutch practices. The American Review of Public Administration, 2014. 44(1): p. 17-34.

11. Ruddell, R., Jones, Nicholas, Social media and policing: matching the message to the audience. Safer Communities, 2013. 12(2): p. 64-70.

12. Porumbescu, G.A., Linking public sector social media and e-government website use to trust in government. Government Information Quarterly, 2016. 33: p. 291-304.

13. Warren, A.M., A. Sulaiman, and N.I. Jaafar, Social media effects on fostering online civic engagement and building citizen trust and trust in institutions. Government Information Quarterly, 2014. 31(2): p. 291-301.

14. Weitzer, R. and S.A. Tuch, Determinants of public satisfaction with the police. Police quarterly, 2005. 8(3): p. 279-297.

15. Zhao, J.S., M. Schneider, and Q. Thurman, The effect of police presence on public fear reduction and satisfaction: A review of the literature. The Justice Professional, 2002. 15(3): p. 273-299.

16. Hawdon, J. and J. Ryan, Police-resident interactions and satisfaction with police: An empirical test of community policing assertions. Criminal justice policy review, 2003. 14(1): p. 5574.

17. Schneider, M.C., Tawandra Rowell, and Veh Bezdikian, The impact of citizen perceptions of community policing on fear of crime: Findings from twelve cities. Police Quarterly 2003. 6(4): p. 363-386.

18. Gill, C., et al., Community-oriented policing to reduce crime, disorder and fear and increase satisfaction and legitimacy among citizens: A systematic review. Journal of Experimental Criminology, 2014. 10(4): p. 399-428.
19. Brainard, L.A., and Teresa Derrick-Mills, Electronic commons, community policing, and communication: Online police-citizen discussion groups in Washington, DC. Administrative Theory \& Praxis 2011. 33(3): p. 383-410.

20. Morgan, M., Cultivation analysis and media effects. The Sage handbook of media processes and effects, 2009: p. 69-82.

21. Shanahan, J.a.M., M., Television and its viewers: Cultivation theory and research. 1999, Cambridge/New York: Cambridge University Press.

22. Lindsay, B.R. Social media and disasters: Current uses, future options, and policy considerations. 2011; Available from: https://ofti.org/wpcontent/uploads/2012/07/42245 gri-04-112011.pdf.

23. Quick, B.L., The effects of viewing Grey's Anatomy on perceptions of doctors and patient satisfaction. Journal of Broadcasting \& Electronic Media, 2009. 53(1): p. 38055.

24. Howell, S.E., Perry, H. L., and Vile, M. , Black cities/white cities: Evaluating the police. Political Behavior, 2004. 26(1): p. 45-68.

25. Gallagher, C., et al., The public image of the police. 2001.

26. Cheurprakobkit, S., Police-citizen contact and police performance attitudinal differences between Hispanics and non-Hispanics. Journal of Criminal Justice, 2000. 28(4): p. 325-336.

27. Morin, R. and R. Stepler, The racial confidence gap in police performance. Pew Research Center, 2016.

28. Rosenbaum, D.P., et al., Attitudes toward the police: The effects of direct and vicarious experience. Police quarterly, 2005. 8(3): p. 343365.

29. Bird, D.L., Megan; Haynes, Katharine, Flooding Facebook - the use of social media during the Queensland and Victorian floods. Australian Journal of Emergency Management, The 2012. 27(1).

30. Gerbner, G., et al., Growing up with television: Cultivation processes. Media effects: Advances in theory and research, 2002. 2: p. 43-67. 